\title{
Microstructure and Tribocorrosion Properties of Pulsed Plasma Nitrided Cast CoCr Alloy for Dental Implant Applications
}

\author{
F. Mindivan ${ }^{a, *}$ AND H. Mindivan ${ }^{b}$ \\ ${ }^{a}$ Bilecik Seyh Edebali University, Biotechnology Application and Research Center, 11210 Bilecik, Turkey \\ ${ }^{b}$ Bilecik Seyh Edebali University, Department of Mechanical Engineering, 11210 Bilecik, Turkey \\ A medical cast $\mathrm{CoCr}$ alloy was treated by pulsed plasma nitriding process. The alloys were tested for cor- \\ rosion and tribocorrosion performance in a laboratory simulated artificial saliva under controlled electrochemical \\ conditions. Results suggest that the pulsed plasma nitriding process provided lower tendency to corrosion and \\ lower corrosion kinetics under sliding, along with significantly reduced wear loss and decrease in optical density in \\ the simulated artificial saliva solution.
}

DOI: 10.12693/APhysPolA.134.192

PACS/topics: biomaterials, Co-Cr alloy, corrosion, tribocorrosion

\section{Introduction}

Cobalt-chromium (CoCr) alloys are used in prosthetic dentistry due to their very low price in comparison with gold and tantalum alloys, connected with great material properties. Although $\mathrm{CoCr}$ alloys do not present the most favorable elastic modulus for biomedical applications, their tribocorrosion properties are very interesting for use in corrosive and wear environments [1]. $\mathrm{CoCr}$ alloys are used in the manufacturing of crowns, copings, bridges and frameworks [2]. The majority of prosthodontic restorations made of $\mathrm{CoCr}$ are castings of this alloy. However, conventional casting of dental CoCr alloy may have some handicaps, such as shrinkage porosity, inclusion, microcracks and dendritic structure $[2,3]$. The casting defects have a pronounced effect on the ion release in actual practice.

For cast $\mathrm{CoCr}$ alloy the oral environment is very harsh. The presence of such ions as $\mathrm{Cl}^{-}$and $\mathrm{F}^{-}$makes the mouth a very aggressive place for the cast $\mathrm{CoCr}$ alloy. In addition, the mechanical action in the presence of saliva together with the variations of temperature and $\mathrm{pH}$ on the restorative surfaces during mastication and tooth brushing can intensify the corrosive processes that can result in biological, functional and aesthetic issues.

The possible release of toxic $\mathrm{Co}$ and $\mathrm{Cr}$ ions remains a major concern. A low wear is important for biomaterials in order to minimize the liberation of metallic ions which can induce adverse reactions in the body [4]. Therefore, methods to reduce material release from CoCr alloys in the case of dental implants are sought. In particular, application of surface modification techniques to the cast $\mathrm{CoCr}$ alloys has a great technological potential.

\footnotetext{
* corresponding author; e-mail ferda.mindivan@bilecik.edu.tr
}

Since plasma assisted thermo chemical surface treatments improve wear resistance, corrosion resistance and fatigue strength $[5,6]$, pulsed plasma nitriding of the cast $\mathrm{CoCr}$ alloy may be beneficial for medical application. The aim of this research is to investigate the effects of pulsed plasma nitriding treatment on the tribocorrosion properties of the cast $\mathrm{CoCr}$ alloy subjected to sliding wear conditions.

\section{Materials and equipment}

The metal used in this study was a cast $\mathrm{CoCr}$ alloy, with the chemical composition of $61.1 \% \mathrm{Co}, 27.8 \% \mathrm{Cr}$, $8.5 \% \mathrm{~W}$ and $1.7 \% \mathrm{Si}$. The cast Co-Cr alloy corresponded to type III. Before pulsed plasma nitriding process, the surface of the cast $\mathrm{CoCr}$ alloy was ground using 1200 grit $\mathrm{SiC}$ paper and mechanically polished with a fine grade alumina paste. The cast $\mathrm{CoCr}$ alloy was then pulsed plasma nitrided at $793 \mathrm{~K}$ under $0.00025 \mathrm{MPa}$ pressure for $43200 \mathrm{~s}$ in an industrial furnace in a gas mixture of $75 \% \mathrm{~N}_{2}$ and $25 \% \mathrm{H}_{2}$. Samples were cross sectioned and successively ground with $\mathrm{SiC}$ paper (grit 320-1200) and polished mechanically.

Microstructural characterization was made by microscopic examinations, X-ray diffraction (XRD) and microhardness measurements. Microscopic examination was performed on the cross-section of the nitrided layer by utilizing Nikon Eclipse LV150 Light Optic Microscope (LOM). XRD analysis was carried out by utilizing a Panalytical Empyrean diffractometer with $\mathrm{CuK}_{\alpha}$ radiation. The cross-sectional hardness measurements were carried out using Knoop microhardness tester with a load of $100 \mathrm{~g}$ and a dwell time of $10 \mathrm{~s}$ (each measurement was performed at least five times).

The polarisation measurements were performed utilizing a typical three electrode potentiodynamic polarization test unit in a simulated artificial saliva (SAS) at room temperature. Before potentiodynamic polarization 
measurements, an initial delay of $45 \mathrm{~min}$. was employed in order to measure the open circuit potential (OCP) between working and reference electrodes. Potentiodynamic polarization curves were generated by sweeping the potential from cathodic to anodic levels at a scan rate of $1 \mathrm{mVs}^{-1}$, starting from -0.75 up to $+0.15 \mathrm{~V}$. Corrosion potentials $E_{\text {corr }}$ and corrosion current densities $I_{\text {corr }}$ were calculated by fitting, using Tafel software.

The tribocorrosion tests were conducted in the $30 \mathrm{ml}$ of the same electrolyte that used in corrosion tests by using a ball-on-disk reciprocating tribometer coupled with three-electrode electrochemical cell. Reciprocating sliding wear tests were performed in a reciprocating mode with a $1.7 \mathrm{~cm} \mathrm{~s}^{-1}$ sliding rate under $5 \mathrm{~N}$ applied load for $45 \mathrm{~min}$. at OCP conditions. This triboelectrochemical technique was used due to its simplicity for gathering information on the surface state of the sliding metals [7].

The OCP was measured before, during and after sliding, whereas the sliding action started after reaching the stable OCP values for each test. An alumina with ball $10 \mathrm{~mm}$ in diameter was used as the counter body. During the test, surface with an area of $2 \mathrm{~cm}^{2}$ was exposed to the corrosive electrolyte. After tribocorrosion tests, the contact surfaces of samples and alumina balls were ex-

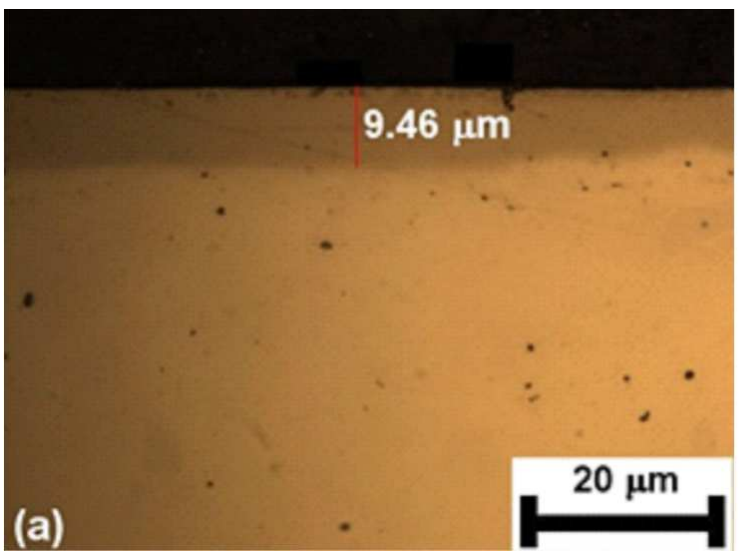

amined under Zeiss Supra Field Emission Gun Scanning Electron Microscope (FEG-SEM) equipped with energy dispersive X-ray spectrometer (EDS) and by LOM.

Finally, wear track profiles were obtained using a contact profilometer (Mitutoyo Surtest SJ-400). By the end of the OCP tribocorrosion tests, optical densities of SAS solution were measured using a UV-spectrophotometer. Freshly prepared SAS was analysed as the reference to evaluate the optical densities of solutions. After the spectrophotometric measurement of freshly prepared SAS solution by using a fixed light wavelength of $250 \mathrm{~nm}$, the obtained data was automatically adjusted to zero in order to determine the optical densities of the SAS solutions utilized in the OCP tribocorrosion tests.

\section{Results and discussion}

Figure 1 shows cross-sectional LOM and SEM images of pulsed plasma nitrided CoCr alloy after polishing. The thickness of the nitriding-affected zone was estimated to be between 9 and $10 \mu \mathrm{m}$ from the metallographic cross section analysis using LOM.

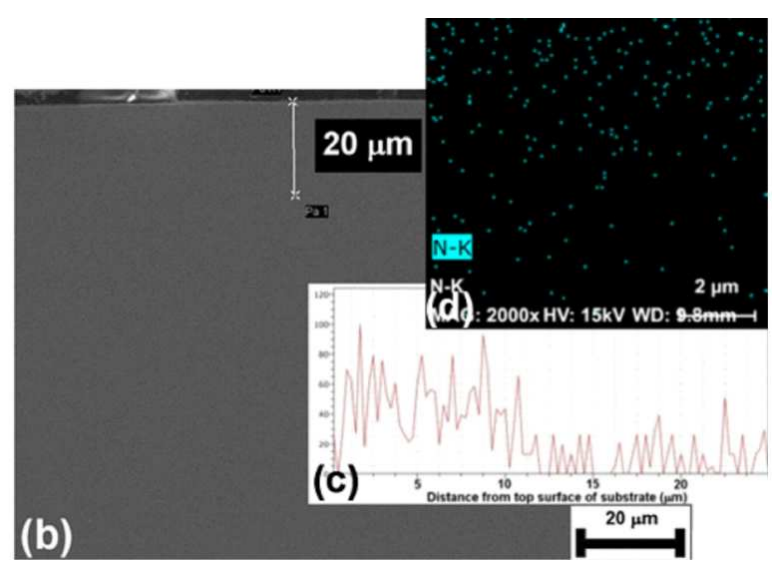

Fig. 1. Cross-sectional LOM (a) and FEG-SEM (b) pictures, EDS line scan (c) and EDS mapping (d), showing the distribution of nitrogen at the surface of a pulsed plasma nitrided $\mathrm{CoCr}$ alloy.

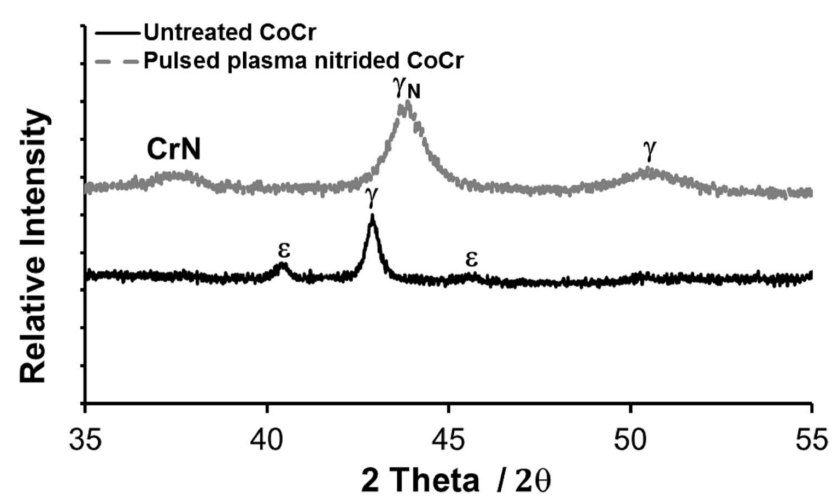

Fig. 2. XRD diagrams of the untreated and pulsed plasma nitrided CoCr.
In order to examine the distribution of the nitrogen in the nitride layer, EDS line scan (Fig. 1c) and EDS mapping (Fig. 1d) were carried out. A depletion of nitrogen, shown in turquoise blue, was recorded from the outer surface to the inner surface of the coating.

The XRD examinations shown in Fig. 2 demonstrate the transformation of the phases in the untreated and pulsed plasma nitrided $\mathrm{CoCr}$ alloys. The results show that the dominant phases in the surface layer of the untreated $\mathrm{CoCr}$ alloy were $\gamma-(\mathrm{CoCr})$ and $\varepsilon-(\mathrm{CoCr})$ cobalt phases.

However, the pulsed plasma nitriding treatment induced new phases corresponding to $\mathrm{CrN}$ and $\gamma \mathrm{N}$ peaks. The $\gamma \mathrm{N}$ phase can form at low temperatures by introducing interstitials (such as $\mathrm{N}$ and $\mathrm{C}$ ) into FCC structured 
substrate with a certain amount of nitride/carbide formers. On the other hand, the $\varepsilon$ phase disappeared after the treatment. The Knoop microhardness measured at the cross-section by indentation increased from $419 \pm 7 \mathrm{HK}_{0.1}$ (untreated CoCr alloy) to $485 \pm 5 \mathrm{HK}_{0.1}$ for pulsed plasma nitrided $\mathrm{CoCr}$ alloy.

Figure 3 presents the potentiodynamic polarization curves for untreated and pulsed plasma nitrided $\mathrm{CoCr}$ alloys. Electrochemical values obtained from the potentiodynamic polarization curves by Tafel extrapolation reveal that after pulsed plasma nitriding process, the corrosion potential $E_{\text {corr }}$ has shifted to more positive value (from $-420 \mathrm{mV}$ to $-198 \mathrm{mV}$ ) and a lower corrosion current density value (from $6.65 \times 10^{-6} \mathrm{Acm}^{-2}$ to $2.6 \times 10^{-6} \mathrm{Acm}^{-2}$ ) was also observed. The depletion of $\mathrm{Cr}$ due to the formation of CrN (Fig. 2) did not seem to play an important role in the corrosion.

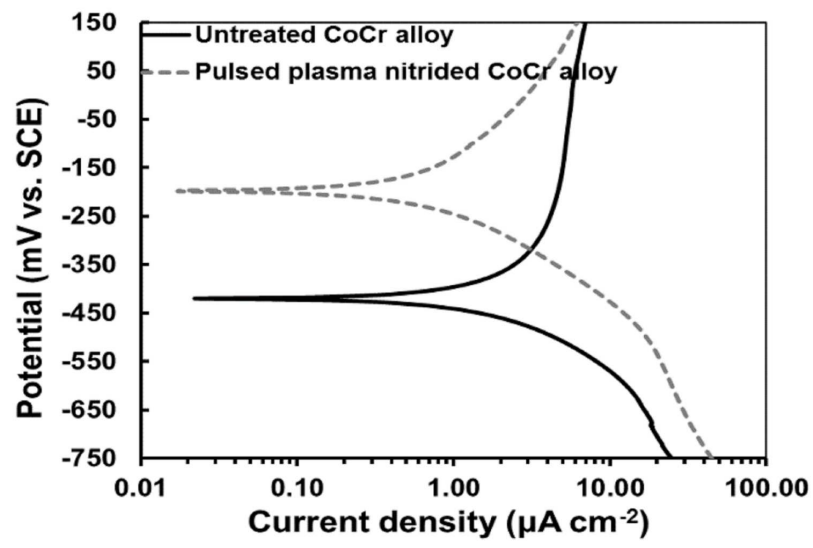

Fig. 3. Potentiodynamic polarization curves of the untreated and pulsed plasma nitrided $\mathrm{CoCr}$.

Figure 4 presents the evolution of OCP with time before, during and after sliding, together with the coefficient of friction (COF) values obtained during the sliding. At the onset of sliding, the OCP of the untreated CoCr alloy shifted to more cathodic values. This was due to both the mechanical breakdown and/or partial removal of the passive film and the formation of active sites located in the wear track [1,7]. During the sliding, the untreated $\mathrm{CoCr}$ alloy presented relatively stable OCP values. At the end of the sliding test, there was an abrupt increase in potential for the untreated $\mathrm{CoCr}$ alloy. This is attributed to the initial impact of loading and formation of a passive film [1, 7].

In the case of pulsed plasma nitrided CoCr alloy, an initial drop in the OCP values at the beginning of the test was observed, and the OCP values increased steadily until the end of the test. After sliding, the potential was restored to a higher value than the initial OCP value. The pulsed plasma nitrided $\mathrm{CoCr}$ alloy always presented relatively higher potentials under sliding, indicating a lower tendency to corrosion. On the other hand, lower and relatively stable COF values were observed for the pulsed plasma nitrided CoCr alloy (Fig. 4b).

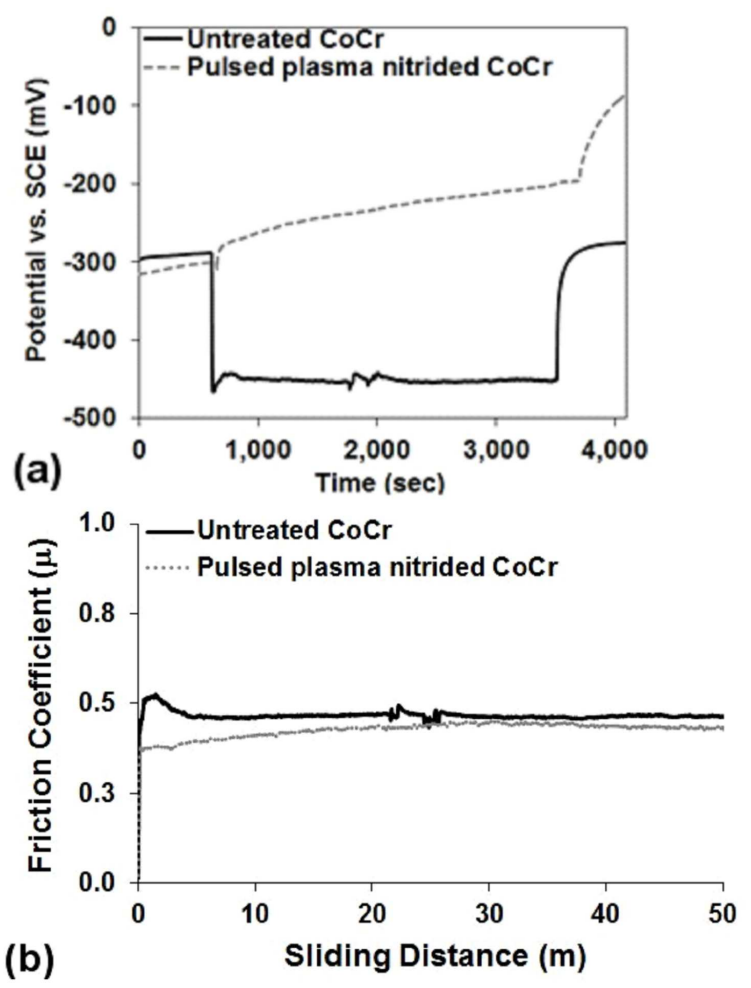

Fig. 4. Evolution of OCP (a) and COF (b) in SAS solution.

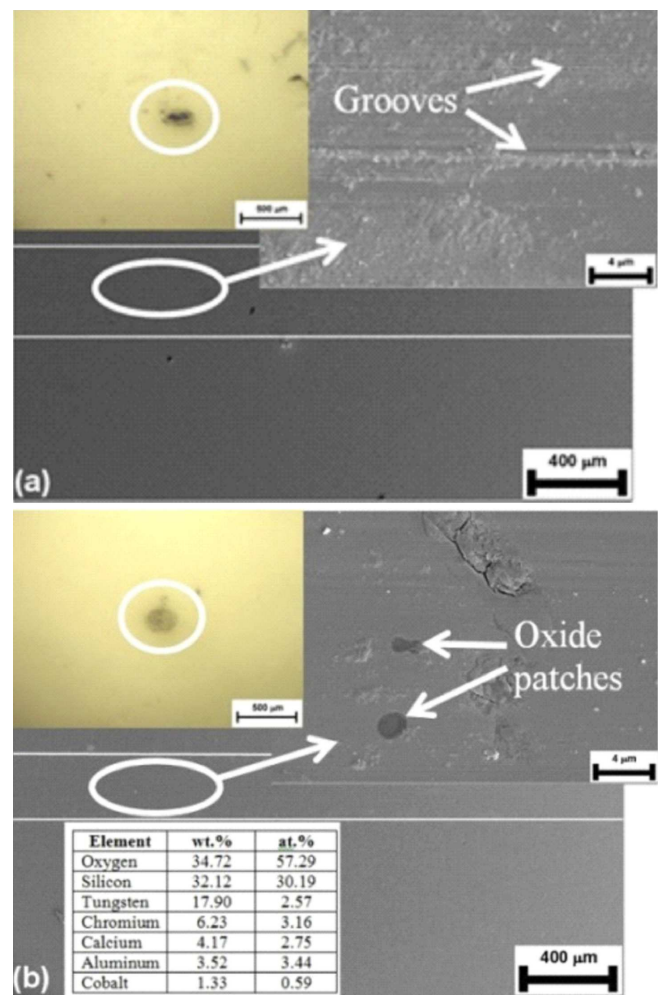

Fig. 5. Low and high magnification SEM micrographs of wear tracks generated on the surface of untreated $\mathrm{CoCr}$ alloy (a), and pulsed plasma nitrided $\mathrm{CoCr}$ alloy (b), and LOM images of their corresponding testing balls after tribocorrosion. 
The low and high magnification views of the wear tracks developed on the samples and their corresponding testing balls are shown in Fig. 5. When two samples are compared, wear grooves in the sliding direction of the untreated $\mathrm{CoCr}$ alloy indicate the abrasive wear that occurs as the result of the penetration of higher asperities of hard alumina ball [7]. The contact surface of the mating alumina ball reveals the material transfer from the untreated CoCr alloy to the periphery of the contact surface of the alumina ball that can be seen in the LOM image (Fig. 5a).

On the other hand, it can be seen in the micrographs together with the representative EDS spectra, taken from the wear track areas, that the effect of oxidative wear was much severe on the pulsed plasma nitrided $\mathrm{CoCr}$ alloy, as compared to the untreated $\mathrm{CoCr}$ alloy. In addition to oxygen, EDS analysis also revealed the presence of $\mathrm{Al}$, pointing at a considerable amount of material transfer from the alumina ball (Fig. 5b).

Accordingly, the untreated $\mathrm{CoCr}$ alloy in the test solution presented the biggest wear volume loss $(22.8 \times$ $10^{-3} \mathrm{~mm}^{3}$ ) and highest optical density value (3.936) as compared to the wear volume $\left(6.99 \times 10^{-3} \mathrm{~mm}^{3}\right)$ and formation of wear debris (3.032) of the pulsed plasma nitrided $\mathrm{CoCr}$ alloy. The difference in total wear volume loss values between the untreated and pulsed plasma nitrided $\mathrm{CoCr}$ alloys can be explained by the increased hardness of the pulsed plasma nitrided CoCr alloy and the decreased corrosion tendency of the pulsed plasma nitrided CoCr alloy due to the thickening of the passive film, leading to the formation of a film enriched in $\mathrm{Cr}_{2} \mathrm{O}_{3}$ with higher chemical stability [8].

\section{Conclusions}

- According to the potentiodynamic polarization test results, the pulsed plasma nitriding process did not accelerate the corrosion process.

- The pulsed plasma nitriding process affected the tribocorrosion behaviour of cast $\mathrm{CoCr}$ alloy, where lower COF, higher OCP, lower wear volume loss and lower amount of wear debris accumulated in SAS solution were observed.

- The wear mechanisms were identified as abrasive wear for cast $\mathrm{CoCr}$ alloy and oxidative wear for pulsed plasma nitrided $\mathrm{CoCr}$ alloy.

\section{References}

[1] F. Mindivan, M.P. Yildirim, F. Bayindir, H. Mindivan, Acta Phys. Pol. A 129, 701 (2016).

[2] L. Reimann, L.A. Dobrzański, Arch. Mater. Sci. Eng. 60, 5 (2013).

[3] J.V. Giacchi, C.N. Morando, O. Fornaro, H.A. Palacio, Mater. Charact. 62, 53 (2011).

[4] G. Schmalz, P. Garhammer, Dent. Mater. 18, 396 (2002).

[5] J.A. Ortega-Saenz, M.A.L. Hernandez-Rodriguez, V. Ventura-Sobrevilla, R. Michalczewski, J. Smolik, M. Szczerek, Wear 271, 2125 (2011).

[6] X. Luo, X.Li, Y.Sun, H.Dong, Wear 302, 1615 (2013).

[7] H. Mindivan, Mach. Technol. Mater. 12, 58 (2016).

[8] M.A. Arenas, A. Conde, J.J. De Damborenea, Metall. Mater. Trans. A 44, 4382 (2013). 